\title{
EFFECT OF VAN DER WAALS INTERACTIONS ON THE PHONON DYNAMICS IN USe
}

\author{
Atul Pandey ${ }^{\mathrm{a}}$ and K.S. Upadhyaya ${ }^{\mathrm{b}}$ \\ ${ }^{a}$ Department of Physics, K. N. Govt. P. G. College Gyanpur, Sant Ravidas Nagar Bhadohi-221304, Uttar Pradesh, India \\ ${ }^{\mathrm{b}}$ Smt. Indira Gandhi Government Degree College, Lalganj, Mirzapur, Uttar Pradesh, India \\ E-mail: kripa1shankar@yahoo.com
}

Received 28 April 2006

\begin{abstract}
Van der Waals three body force shell model (vTSM), which includes the effect of van der Waals interactions (vWI) and three body interactions in the framework of both ions polarizable rigid shell model (RSM), has been employed to study the crystal dynamics of USe. We assume that the overlap repulsion is effective only up to the first neighbour, while the van der Waals attraction acts up to the second neighbours and plays very important role. The agreement between our predictions and experimental data for phonon dispersion curves strongly supports the inclusion of van der Waals interactions. We also report the specific heat variations, two phonon IR/Raman spectra, and anharmonic properties of USe.
\end{abstract}

Keywords: Lattice vibrational properties, phonons, dispersion curves

PACS: 63.20.-e, 65.40.Ba, 78.30.-j

\section{Introduction}

The NaCl-type uranium monochalcogenides (US, USe, and UTe) show a great variety of interesting physical phenomena and some of them exhibit strong anomalies in the phonon spectra. The nature of these compounds can be well understood by high energy gap, high dielectric constants, and large negative-ion electronic polarizabilities $\left(\alpha^{-}\right)$. Jackman et al. [1] have reported the experimental results on phonon dispersion relations and Rudigier et al. [2-3] have reported on specific heat variations for USe. Jackman et al. [1] have fitted the rigid ion and shell models (RIM and SM) to neutron scattering data but the agreement obtained by them is poor particularly at $\mathrm{X}$ point. The RIM and $\mathrm{SM}$ also fail to explain Cauchy violation $\left(C_{12} \neq C_{44}\right)$ for USe. Lattice dynamics of uranium chalcogenides (including USe) have been studied by Jha et al. [4] by using three body force rigid ion model which includes long range three body interactions due to charge transfer effects [5] but three body force rigid ion model (TRIM) has failed to explain phonon anomalies in these compounds. In another attempt, Jha and Sanyal [6] employed three body force rigid shell model which incorporated long range three body interactions in the framework of rigid shell model. The three body force shell model (TSM) has explained the phonon discrep- ancies slightly better than the three body force rigid ion model (TRIM) but still discrepancies are observed along $(q 00)$ and $(q q 0)$ directions. Further, TSM could not explain the zero splitting of optical phonon frequency at X point. Later on, Jha and Sanyal [7] have employed breathing shell model [8] in which they considered the breathing motion of electron shells. They also compare their results with TRIM and neutron scattering data; although the results are better than those reported by using TRIM and TSM, yet they are not entirely satisfactory and failure of the model can be seen more along $(q 00)$ for optical branches. Further, breathing shell model (BSM) less satisfactorily explains the discrepancies observed along $(q q 0)$ direction. In order to explain the lattice vibrational behaviour of USe better, the present authors have employed a model VTSM which includes the effects of van der Waals interactions and three body interactions in the framework of both ions polarizable rigid shell model. This model has already been used for the study of lattice dynamics of lead chalcogenides [9] and US [10] .

\section{Theory}

The general formalism of van der Waals three body force shell model, vTSM, can be derived from the 
crystal potential whose relevant expression per unit cell is given by

$$
\Phi=\Phi^{\mathrm{C}}+\Phi^{\mathrm{R}}+\Phi^{\mathrm{TBI}}+\Phi^{\mathrm{vWI}},
$$

where the first term $\Phi^{\mathrm{C}}$ is Coulomb interaction potential and is long-range in nature, the second term $\Phi^{\mathrm{R}}$ is short-range overlap repulsion potential, the third term $\Phi^{\mathrm{TBI}}$ is three body interactions potential, and the last term $\Phi^{\mathrm{vWI}}$ is van der Waals interaction potential and owes its origin to the correlations of the electron motions in different atoms.

Using the crystal expression (1) and introducing the effect of van der Waals interaction (vWI) and three body interactions (TBI), the secular determinant

$$
\left|\mathbf{D}(q)-\omega^{2} \mathbf{M I}\right|=0
$$

is obtained for the frequency determination, where $\mathbf{D}(q)$ is the $6 \times 6$ dynamical matrix, $\mathbf{M}$ is the diagonal matrix representing the ionic masses, and $\mathbf{I}$ represents unit $6 \times 6$ matrix.

If we consider the second neighbour dipole-dipole van der Waals interaction energy, then it is expressed as

$$
\Phi_{\mathrm{dd}}^{\mathrm{vWI}}(r)=-S_{\mathrm{v}}\left|\frac{C_{++}+C_{--}}{6 r^{6}}\right|=\Phi^{\mathrm{v}}(r),
$$

where $S_{\mathrm{v}}$ is a lattice sum and the constants $C_{++}$and $C_{--}$are the van der Waals coefficients corresponding to the positive-positive and negative-negative ion pairs, respectively. A detailed theory of present model (vTSM) has been reported elsewhere [10].

\section{Computations and results}

We have calculated our twelve model parameters by using interatomic separation $r_{0}$, elastic constants $C_{11}$, $C_{12}$, and $C_{44}$, frequencies $\nu_{\mathrm{LO}}(\Gamma)=\nu_{\mathrm{TO}}(\Gamma), \nu_{\mathrm{LO}}(\mathrm{L})$, $\nu_{\mathrm{TO}}(\mathrm{L}), \nu_{\mathrm{LA}}(\mathrm{L})$, and $\nu_{\mathrm{TA}}(\mathrm{L})$, electronic polarizabilities $\alpha_{1}$ and $\alpha_{2}$, and van der Waals coefficients $C_{++}$, $C_{--}$and have presented them in Table 1. These parameters have been employed to calculate the phonon dispersion curves for USe and have been shown in Fig. 1. The calculated phonon dispersion curves (PDC) have also been compared with the experimental data [1]. The adequacies of van der Waals three body force shell model (vTSM) have been further tested by studying specific heat variations and two phonon IR / Raman spectra. For this we have computed the specific heats at constant volume and pressure $\left(C_{\mathrm{v}} / T\right.$ and $\left.C_{\mathrm{p}} / T\right)$ from the phonon spectra, plotted against the square of temperature $\left(T^{2}\right)$, and presented along with measured data

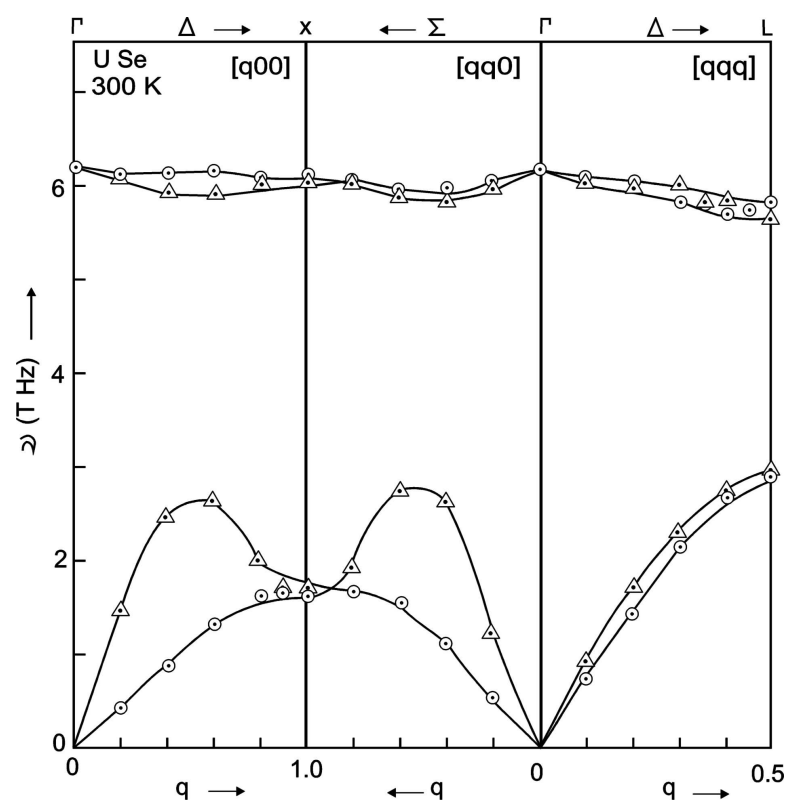

Fig. 1. Phonon dispersion curves for USe: $\triangle$ are longitudinal, $\odot$ are transverse experimental points, - is present study.

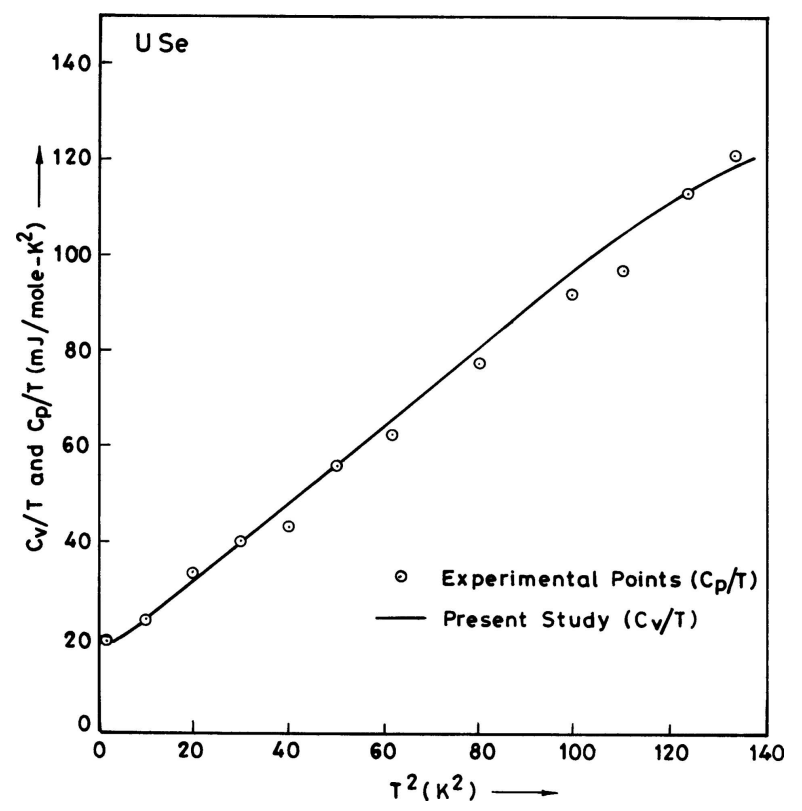

Fig. 2. Specific heat at constant volume and pressure $\left(C_{\mathrm{v}} / T\right.$ and $\left.C_{\mathrm{p}} / T\right)$ as a function of $T^{2}$.

in Fig. 2. In order to study the second order IR and Raman spectra we have employed the critical point analysis [11]. A comparison of combined density of states (CDS) peaks and their assignments from IR/Raman scattering spectra with the help of neutron data [1] and the present study is shown in Table 2. We have also studied the anharmonic elastic properties by calculating third and fourth order elastic constants as they provide physical insight into the nature of binding forces between the constituents of a crystal. The expressions 
Table 1. Input data and model parameters for USe.

\begin{tabular}{lcclr}
\hline Properties & Values & Ref. & Parameters & Values \\
\hline$C_{11}\left(10^{12}\right.$ dyne $\left./ \mathrm{cm}^{2}\right)$ & 2.01 & {$[7]$} & $Z_{\mathrm{m}}^{2}$ & 2.0821 \\
$C_{12}\left(10^{12}\right.$ dyne $\left./ \mathrm{cm}^{2}\right)$ & 0.00 & {$[7]$} & $r_{0} f_{0}^{\prime}$ & -0.1076 \\
$C_{44}\left(10^{12}\right.$ dyne $\left./ \mathrm{cm}^{2}\right)$ & 0.17 & {$[7]$} & $A_{12}$ & 37.6977 \\
$\nu_{\mathrm{LO}}(\Gamma)=\nu_{\mathrm{TO}}(\Gamma)(\mathrm{THz})$ & 6.20 & {$[1]$} & $B_{12}$ & -2.8709 \\
$\nu_{\mathrm{LO}}(\mathrm{L})(\mathrm{THz})$ & 5.88 & {$[1]$} & $A_{11}$ & -11.3557 \\
$\nu_{\mathrm{TO}}(\mathrm{L})(\mathrm{THz})$ & 5.90 & {$[1]$} & $B_{11}$ & 21.2040 \\
$\nu_{\mathrm{LA}}(\mathrm{L})(\mathrm{THz})$ & 2.97 & {$[1]$} & $A_{22}$ & 8.2385 \\
$\nu_{\mathrm{TA}}(\mathrm{L})(\mathrm{THz})$ & 2.96 & {$[1]$} & $B_{22}$ & -20.7587 \\
$r_{0}\left(10^{-8} \mathrm{~cm}\right)$ & 2.87 & {$[7]$} & $d_{1}$ & 0.2196 \\
$\alpha_{1}\left(10^{-24} \mathrm{~cm}^{3}\right)$ & 0.41 & {$[7]$} & $d_{2}$ & 1.6625 \\
$\alpha_{2}\left(10^{-24} \mathrm{~cm}^{3}\right)$ & 7.00 & {$[7]$} & $Y_{1}$ & -3.4909 \\
$C_{++}\left(10^{-60} \mathrm{erg} \mathrm{cm}^{6}\right)$ & 1428 & {$[13]$} & $Y_{2}$ & -7.8724 \\
$C_{--}\left(10^{-60} \mathrm{erg} \mathrm{cm}^{6}\right)$ & 792 & {$[13]$} & & \\
\hline
\end{tabular}

Table 2. Assignments of two-phonon Raman and infra-red peaks for USe.

\begin{tabular}{|c|c|c|c|c|c|c|}
\hline \multirow{3}{*}{$\begin{array}{c}\text { CDS } \\
\text { peaks } \\
\left(\mathrm{cm}^{-1}\right)\end{array}$} & \multicolumn{3}{|c|}{ Raman active } & \multicolumn{3}{|c|}{ Infra-red active } \\
\hline & \multirow{2}{*}{$\begin{array}{l}\text { Peaks, Ref. [1] } \\
\quad\left(\mathrm{cm}^{-1}\right)\end{array}$} & \multicolumn{2}{|c|}{ Present study } & \multirow{2}{*}{$\begin{array}{l}\text { Peaks, Ref. [1] } \\
\quad\left(\mathrm{cm}^{-1}\right)\end{array}$} & \multicolumn{2}{|c|}{ Present study } \\
\hline & & Assignments & Values $\left(\mathrm{cm}^{-1}\right)$ & & Assignments & Values $\left(\mathrm{cm}^{-1}\right)$ \\
\hline 57 & - & - & - & - & - & - \\
\hline \multirow[t]{2}{*}{107} & 110 & $2 \mathrm{TA}(\Delta)$ & 104 & 110 & $2 \mathrm{TA}(\Delta)$ & 104 \\
\hline & & $2 \mathrm{TA}(\mathrm{X})$ & 110 & - & - & - \\
\hline 125 & 123 & $\mathrm{LA}+\mathrm{TA}(\Delta)$ & 120 & 123 & $\mathrm{LA}+\mathrm{TA}(\Delta)$ & 120 \\
\hline \multirow[t]{3}{*}{143} & 146 & $\mathrm{TO}-\mathrm{TA}(\Delta)$ & 148 & - & - & - \\
\hline & 147 & TO-LA $(\mathrm{X})$ & 140 & - & - & - \\
\hline & & LO-LA $(\mathrm{X})$ & 143 & - & - & - \\
\hline 165 & - & - & - & - & - & - \\
\hline \multirow[t]{2}{*}{193} & 194 & $2 \mathrm{TA}(\mathrm{L})$ & 194 & - & - & - \\
\hline & 196 & $\mathrm{LA}+\mathrm{TA}(\mathrm{L})$ & 199 & - & - & - \\
\hline 230 & - & - & - & - & - & - \\
\hline 247 & - & - & - & - & - & - \\
\hline \multirow[t]{5}{*}{260} & 258 & $\mathrm{LO}+\mathrm{TA}(\Delta)$ & 257 & 258 & $\mathrm{LO}+\mathrm{TA}(\Delta)$ & 257 \\
\hline & 259 & $\mathrm{TO}+\mathrm{TA}(\mathrm{X})$ & 255 & - & - & - \\
\hline & & $\mathrm{LO}+\mathrm{TA}(\mathrm{X})$ & 258 & - & - & - \\
\hline & 261 & $\mathrm{TO}+\mathrm{LA}(\mathrm{X})$ & 261 & - & - & - \\
\hline & & $\mathrm{LO}+\mathrm{LA}(\mathrm{X})$ & 263 & - & - & - \\
\hline \multirow[t]{2}{*}{288} & - & - & - & 288 & TO+TA(L) & 289 \\
\hline & & & & 290 & $\mathrm{TO}+\mathrm{LA}(\mathrm{L})$ & 294 \\
\hline 298 & - & - & - & 295 & $\mathrm{LO}+\mathrm{LA}(\mathrm{L})$ & 300 \\
\hline 327 & - & - & - & - & - & - \\
\hline 355 & - & - & - & - & - & - \\
\hline \multirow[t]{2}{*}{388} & 387 & $\mathrm{LO}+\mathrm{TO}(\mathrm{L})$ & 390 & - & - & - \\
\hline & 392 & $2 \mathrm{LO}(\mathrm{L})$ & 396 & - & - & - \\
\hline \multirow[t]{4}{*}{407} & 406 & $2 \mathrm{LO}(\Delta)$ & 410 & 406 & $2 \mathrm{LO}(\Delta)$ & 410 \\
\hline & 408 & $2 \mathrm{TO}(\mathrm{X})$ & 400 & - & - & - \\
\hline & & $\mathrm{LO}+\mathrm{TO}(\mathrm{X})$ & 403 & - & - & - \\
\hline & & $2 \mathrm{LO}(\mathrm{X})$ & 406 & - & - & - \\
\hline
\end{tabular}


Table 3. Third and fourth order elastic constants (in units $10^{12}$ dyne $/ \mathrm{cm}^{2}$ ) for USe.

\begin{tabular}{lrlr}
\hline Property & Value & Property & Value \\
\hline$C_{111}$ & 684.9202 & $C_{1122}$ & 2.1527 \\
$C_{112}$ & -0.3420 & $C_{1266}$ & 2.5310 \\
$C_{166}$ & -0.5598 & $C_{4444}$ & 2.3288 \\
$C_{123}$ & 0.3273 & $C_{1123}$ & -0.8834 \\
$C_{144}$ & 0.4288 & $C_{1144}$ & -1.2409 \\
$C_{456}$ & 0.4795 & $C_{1244}$ & -1.0417 \\
$C_{1111}$ & 783.6910 & $C_{1456}$ & -1.2181 \\
$C_{1112}$ & 0.4296 & $C_{4456}$ & -0.9702 \\
$C_{1166}$ & 1.8076 & & \\
\hline
\end{tabular}

Table 4. Values of pressure derivatives of SOE and TOE constants for USe.

\begin{tabular}{lr}
\hline Property & Value \\
\hline $\mathrm{d} K / \mathrm{d} P$ & 6.5750 \\
$\mathrm{~d} S / \mathrm{d} P$ & 8.2181 \\
$\mathrm{~d} C_{44} / \mathrm{d} P$ & -1.0571 \\
$\mathrm{~d} C_{111} / \mathrm{d} P$ & -1409.5924 \\
$\mathrm{~d} C_{112} / \mathrm{d} P$ & -1.3347 \\
$\mathrm{~d} C_{166} / \mathrm{d} P$ & 1.9728 \\
$\mathrm{~d} C_{123} / \mathrm{d} P$ & 1.8301 \\
$\mathrm{~d} C_{144} / \mathrm{d} P$ & 0.0140 \\
$\mathrm{~d} C_{456} / \mathrm{d} P$ & 2.1024 \\
\hline
\end{tabular}

for these elastic constants and pressure derivatives of second order elastic constants (SOEC) are similar to those derived by Puri, Verma, and Garg [12] for $\mathrm{NaCl}$ structure. The third order $\left(C_{111}, C_{112}, C_{166}, C_{123}\right.$, $\left.C_{144}, C_{456}\right)$ and fourth order $\left(C_{1111}, C_{1112}, C_{1166}\right.$, $C_{1122}, C_{4444}, C_{1123}, C_{1144}, C_{1244}, C_{1456}, C_{4456}$ ) elastic constants are shown in Table 3 , while the pressure derivatives of second and third order elastic constants $\left(\mathrm{d} C_{44} / \mathrm{d} P, \mathrm{~d} C_{111} / \mathrm{d} P, \mathrm{~d} C_{112} / \mathrm{d} P, \mathrm{~d} C_{166} / \mathrm{d} P\right.$, $\mathrm{d} C_{123} / \mathrm{d} P, \mathrm{~d} C_{144} / \mathrm{d} P$, and $\mathrm{d} C_{456} / \mathrm{d} P$ ) of USe have been presented in Table 4 .

\section{Discussion and conclusion}

The computed phonon dispersion curves displayed in Fig. 1 show that the inclusion of van der Waals interaction have improved the agreement between experimental data [1] and our results. The inclusion of van der Waals interaction (vWI) with TBI have influenced both longitudinal and transverse optic modes much more than acoustic branches. The agreement between theory and experimental data at X point is also excellent. Another striking feature of the present model is noteworthy from the excellent reproduction of almost all branches. Hence the predictions of phonon dispersion curves (PDC) for USe using vTSM may be con-

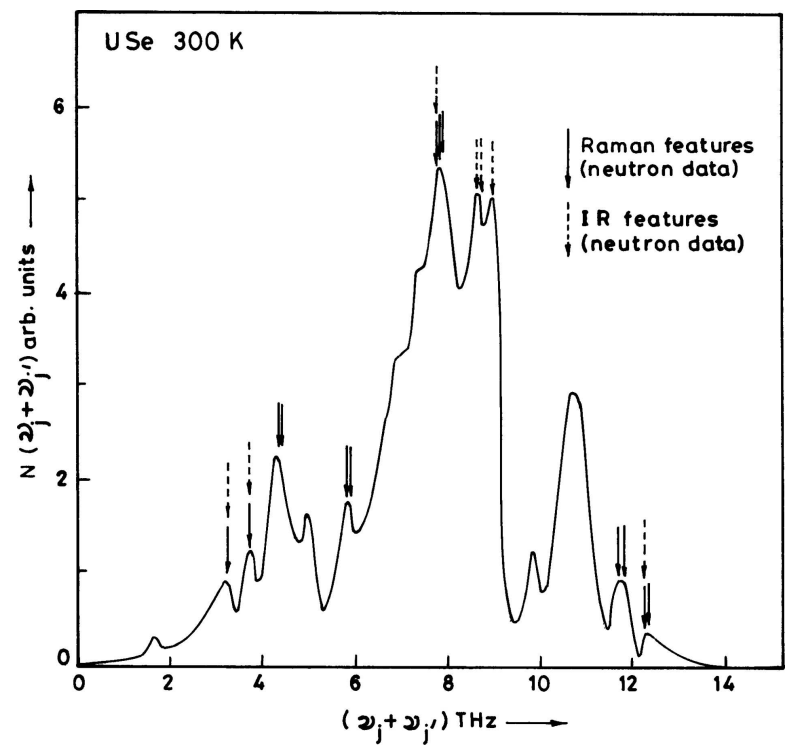

Fig. 3. Combined density of states curve for USe.

sidered more satisfactory than those from other models $[1,4,6-7]$.

We have plotted the variation of specific heat at constant volume and pressure $\left(C_{\mathrm{v}} / T\right.$ and $\left.C_{\mathrm{p}} / T\right)$ with the square of temperature $\left(T^{2}\right)$. It is evident from the Fig. 2 that our results are in good agreement with measured data [2] and are generally better than those of breathing shell model (BSM) [6]. The combined density of states by using vTSM for USe has been plotted in Fig. 3. The basic aim of the study of two phonon IR / Raman scattering spectra is to correlate the neutron and optical experimental data for USe. We have also investigated the anharmonic properties of USe by using vTSM. This includes the predictions of third and fourth order elastic constants and the pressure derivatives of SOE and TOE constants. Since no experimental values on these properties have been reported so far, we are unable to comment as such on the reliability of our results.

In this paper we have systematically reported phonon dispersion curves, specific heat variations, combined density of states, and anharmonic properties of USe. On the basis of overall fair agreement, it may be concluded that the present model, van der Waals three body force shell model (vTSM), is adequately capable to describe the crystal dynamics of USe.

\section{Acknowledgements}

The authors are grateful to the computer centre, B.H.U., Varanasi for computational assistance. They are also indebted to Prof. S.P. Sanyal and Dr P.K. Jha for many useful discussions. 


\section{References}

[1] J.A. Jackman, T.M. Holden, and W.J.L. Buyers, Systematic study of the lattice dynamics of the uranium rocksalt-structure compounds, Phys. Rev. B 33, 71447153 (1986).

[2] H. Rudigier, H.R. Ott, and O. Vogt, Low-temperature specific heat of uranium monopnictides and monochalcogenides, Phys. Rev. B 32, 4584-4591 (1985).

[3] H. Rudigier, H.R. Ott, and O. Vogt, Low-temperature specific heat of uranium monopnictides and monochalcogenides, Physica B 130, 538-540 (1985).

[4] P.K. Jha and S.P. Sanyal, Lattice dynamics of uranium chalcogenides and pnictides, Phys. Rev. B 46, 36643667 (1992).

[5] R.K. Singh, Many-body interactions in binary ionic solids, Phys. Rep. 85, 259-401 (1982).

[6] P.K. Jha, R.K. Singh, and S.P. Sanyal, Phonon anomalies in uranium chalcogenides, Physica B 174, 101104 (1991).

[7] P.K. Jha and S.P. Sanyal, Lattice vibrational properties of uranium chalcogenides, Physica B 216, 125-
131 (1995).

[8] V. Nusslein and U. Schroder, Calculations of dispersion curves and specific heats for $\mathrm{LiF}$ and $\mathrm{NaCl}$ using the breathing shell model, Phys. Status Solidi B 21, 309-314 (1967).

[9] K.S. Upadhyaya, M. Yadav, and G.K. Upadhyaya, Lattice dynamics of IV-VI ionic semiconductors: An application to lead chalcogenides, Phys. Status Solidi B 229, 1129-1138 (2002).

[10] K.S. Upadhyaya, Atul Pandey, and D.M. Srivastava, A study of the phonon properties of uranium monochalcogenides: US as an example, Chinese J. Phys. 44(20), 127-136 (2006).

[11] C. Smart, G.R. Wilkinson, A.M. Karo, and J.R. Hardy, Lattice Dynamics, ed. R.F. Wallis (Pergamon Press, Oxford, 1965).

[12] D.S. Puri, V.K. Garg, and M.P. Verma, Many-body effects on 3rd-order elastic constants and pressure derivatives of 2nd-order elastic constants of $\mathrm{CsCl}$ structure solids, Phys. Status Solidi B 78, 113-122 (1976).

[13] L.P. Sharma, $\mathrm{PhD}$ thesis, Agra University, Agra, India (1979).

\title{
VAN DER VALSO SĄVEIKŲ ITAKA USE FONONU DINAMIKAI
}

\author{
Atul Pandey ${ }^{a}$, K.S. Upadhyaya ${ }^{b}$ \\ ${ }^{a}$ Valstybinis koledžas, Džanpūras, Indija \\ ${ }^{\mathrm{b}}$ Indiros Gandi valstybinio laipsnio koledžas, Lalgandžas, Indija
}

\begin{abstract}
Santrauka
Van der Valso (van der Waals) trijų kūnų sąveikos sluoksninis modelis, apimantis van der Valso sąveikų itaką ir trijų kūnų sąveikas pagal abieju jonu poliarizuojamų kietu sluoksnių modelį, panaudotas tirti USe kristalų gardelès dinamikai. Tariama, kad stūma dèl sanklotos veikia tik pirmuosius kaimynus, o tuo tarpu van der
\end{abstract}

Valso trauka veikia ir antruosius ir yra labai svarbi. Teoriškai numatytų rezultatų ir eksperimentiškai gautu duomenu apie fononų dispersijos kreives sutapimas patvirtina, kad turi būti atsižvelgiama $\mathfrak{i}$ van der Valso sąveikas. Taip pat pateiktos savitosios šilumos variacijos, dvifononiai IR ir Ramano spektrai ir anharmoninès USe savybès. 